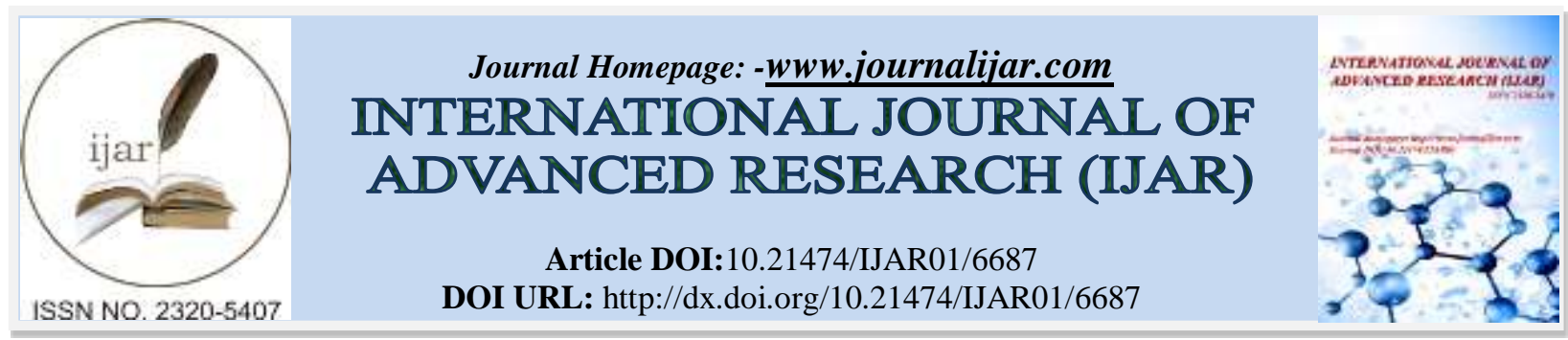

RESEARCH ARTICLE

\title{
THE COMBINATION OF FEATURE ORDE 1 (STATISTICS FEATURE), FEATURE ORDE 2 (FEATURE HARALIC) AND DISCRETE COSINE TRANSFORM (DCT) ON PATTERN ROCOGNITION OF FACE IMAGE.
}

\author{
Juliansyah Putra Tanjung ${ }^{1}$, Muhammad Zarlis ${ }^{2}$ and Marwan Ramli ${ }^{3}$. \\ 1. Master of Informatics Engineering, Fasilkom TI, University of North Sumatra. \\ 2. Fasilkom TI, University of North Sumatra. \\ 3. Science Faculty, University of North Sumatra.
}

\section{Manuscript Info}

Manuscript History

Received: 07 January 2018

Final Accepted: 09 February 2018

Published: March 2018

Keywords:-

Face, Statistic Feature, Feature Haralic, DCT (Discrete Cosine Transform).

\begin{abstract}
Face is an identity to recognize a person, everyone can recognize faces well and distinguish individual faces that had been identified previously in any circumstances, however whether a computer system is able to do the same as humans? The matters should be studied and developed. One of ways to identify the face image is by extracting features including Statistic Feature, Feature Haralic and DCT (Discrete Cosine Transform). It is very necessary to analyze the performance of the three methods by determining which one has better value in pattern recognition of face image, the object that will be recognized is the object of the face image with the number of samples is 1400 images with seven categories: face image with orientation $15^{\circ}$ to left, $0^{\circ}$ and $15^{\circ}$ to right. The first stage that will be carried out is the process of grayscale and continued with the performance of feature extraction that is the performance of statistics feature (Feature Order One) with a level of accuracy of $65.54 \%$, Performance Haralic Feature (Feature Order Two) with the level of accuracy of $50.89 \%$, a combination of performance of Discrete Cosine Transform (DCT) with Statistics feature (feature Order One) with a level of accuracy of 7:14\%, and performance of combination of Discrete Cosine Transform (DCT) with Haralic feature (feature Order Two) with the level of accuracy of $11.6 \%$.
\end{abstract}

Copy Right, IJAR, 2018,. All rights reserved.

\section{Introduction:-}

Pattern Recognition is a study to learn a pattern feature that has previously been saved in a computer system, then a comparison is conducted to another pattern in order to determine the level of accuracy and similarity.

Pattern recognition can be divided into three things such as the mindset pattern, syntactic pattern, and the nervous pattern. Statistical pattern recognition is considered as statistical base, which is usually used for classification algorithm. Those techniques are to analyze the pattern structure of the image. Neural pattern recognition is a combination of statistical and syntactic recognition. In the nervous pattern recognition, the more frequent the system is trained, the better the system will be resulted from. This is part of the artificial neural network in identifying pattern (Gonzalez, 1992). 
The facial recognition system is kind of recognition systems that are difficult to do because level of face variation is so complex that the application will slow down the performance of system in recognizing a face. In contrast, the application of approach which is very complex will affect the accuracy of face recognition (Fadlisyah, 2013)

According Fadlisyah (2013) Statistic Feature can't work so well to recognize the distinction of images. Ardianto V (2015) says that feature Orde 1 (Statistics feature) includes mean, variance, skewness, kurtosis, and entropy that can't be accurately used as features extracted from citrus imagery for classification work as those are only analyzed by an image histogram. Meanwhile, Kamal M says that method of feature Orde 2(Feature Haralic) can't work so well to group individual age with error possibility about to $33 \%$. Based on the result of the study, both methods of feature extraction have yet to be able to work so well to recognize the image pattern. So another algorithm is needed to transform both feature extractions with aim at obtaining a better accuracy level, the Discrete Cosine Transform (DCT) transformation is used to transform the extracted features.

A wide range of computing technologies is becoming increasingly widespread after discovering a variety of feature extractions such as Feature Statistics, Feature Haralic, Gabor Filter, PCA (Principle Componet Analysis) and others.

In this study, a combination of Discrete Cosine Transform (DCT) is conducted with Feature Statistics and Feature Haralic is Feature Extraction

\section{Literature Review:-}

\section{Face Recognition:-}

Face recognition is one of biometric technologies that has been widely applied in security system besides the retina recognition, the fingerprints recognition and iris recognition. For the process, usually it uses a camera to capture a person's face, then compare to a face previously stored in the dataset (Rahim, 2013).

\section{Grayscale:-}

Image of grayscale is kind of images using gray color level. This is one of color in space R (red), G (green), and B (blue) having the same intensity value. The number of bits provided in memory affects the number of existing colors functioning to accommodate the color requirements.

Each pixel sample in the image grayscale can be saved into a 8-bit format which allows 256 intensities and colors defined as the value between 0 and 255, the value 0 is the darkest (black) and the 255 is the whitest. This format will help in programming because it can manipulate bit that is not too much. To make changes on the color image having the matrix value $\mathrm{R}, \mathrm{G}$ and $\mathrm{B}$ to be image grayscale with value $\mathrm{S}$, the conversion can be done by taking the average value of $\mathrm{R}$ (red), $\mathrm{G}$ (green), and B (blue) one (Zhou, H, 2010)

$$
s-\frac{+g+b}{3}
$$

Extraction of feature orde 1 (Feature Statistic):-

The Extraction of feature orde 1 (Feature Statistics) is a extraction method having feature based on the characteristic of an image histogram. This shows the probability of gray level value on an image. From the probability value, it can be calculated that some parameters of feature orde 1 is including mean, skewness, variance, kurtosis, and entropy.

Mean $(\mu)$ :-

it shows the dispersion size of an image

$\mu=\sum_{n} f_{n} p\left(f_{n}\right)$

where $f_{n}$ is a gray intensity value, while $p\left(f_{n}\right)$ indicate the histogram value (the probability of the intensity in the image). 


\section{Skewness ():-}

It indicates the relative slope level of the histogram curve of an image

$\alpha_{3}=\frac{1}{\sigma^{3}} \sum_{n}\left(f_{n}-\mu\right)^{3} p\left(f_{n}\right)$

1. Variance ()

It indicates element variations on the histogram rather than an image

$\sigma^{2}=\sum_{n}\left(f_{n}-\mu\right)^{2} p\left(f_{n}\right)$

2. $\quad$ Kurtosis ()

it indicates relative cricket level of histogram curve on an image

$\alpha_{4}=\frac{1}{\sigma^{4}} \sum_{n}\left(f_{n}-\mu\right)^{4} p\left(f_{n}\right)-3$

3. Entropy $(\mathrm{H})$

it indicates the size of shape irregularity of an image

$H=-\sum_{n} p\left(f_{n}\right) \cdot{ }^{2} \log p\left(f_{n}\right)$

\section{Extraction of feature orde 2 (Feature Haralic):-}

In 1973, Haralick introduced the Gray Level Co-occurrence Matrix (GLCM) in which GLCM functions to perform feature extraction. (Bino, 2012) GLCM uses texture calculations on second-order statistics.

The technique of extracting a statistic of feature orde 2 is by calculating the probability of an adjacency relation between two pixels at a certain distance and angle orientation. This approach works out by forming a matrix kookurency from image data.

The matrix kookurency is a square matrix with the number of elements as many as the square of the number of pixel intensity level in the image. Each point $(p, q)$ in matrix kookurency oriented $\Theta$ has posiblity of a pixel that has value $p$ adjacent to the pixel having value $q$ at a distance $d$ as well as the orientation $\Theta$ and (180 - $\Theta$ ).

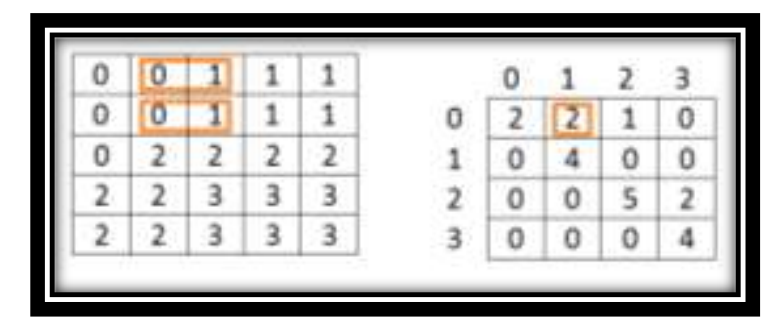

Figure 1:- On the left is image example with 4 gray levels,

On the right are results of GLCM on distance from $1-0$ levels

After obtaining kookurensi matrixs, those can be calculated by some parameters of feature orde 2 included, Angular Second Moment, Contrast, Correlation, Variance, Inverse Difference Moment, and Entropy

Angular Second Moment:-

It shows the size of the homogeneity.

$$
A S M=\sum_{i} \quad \sum_{j}\{p(i, j)\}^{2}
$$

where $p(i, j)$ is the value of row $i$ and column $j$ on the matrix kookurency. 


\section{Contrast:-}

It indicates the size of the dispersion (moment of inertia) of the elements of the image matrix. If the location is far from the main diagonal, the value of contrast is large. Visually, the value of contrast is a measure of variation among the gray levels of an image area.

$$
\text { CON }=\sum_{k} k^{2}\left[\sum_{j} k^{2}\right]
$$

$[i-j]=k$

\section{Correlation:-}

It shows the size of the linear dependence of gray level on image so as to provide clues for the existence of a linear structure on the image.

$\operatorname{COR}=\frac{\sum_{Y} \sum_{j}(i j) \cdot p(i, j)-\mu_{y} \mu_{y}}{\sigma_{,} \sigma_{y}}$

Variance:-

It indicates variations of elements of matrix koocurency. An image with a small gray transition will have a small variance as well.

$V A R=\sum_{i} \sum_{j}\left(i-\mu_{x}\right)\left(j-\mu_{y}\right) p(i, j)$

Inverse Different Moment:-

It indicates the homogeneity of similar gray images. Homogeneous image will have a high IDM price.

$I D M=\sum \sum_{i} \frac{1}{1+(i-j)^{2}} p(i, j)$

\section{Entropy:-}

it shows the size of shape irregularity of high ENT price for images with transition of evenly gray level and has small value if the image structure is irregular (varies).

$E N T_{2}=-\sum \sum p(i, j)^{2} \log p(i, j)$

\section{Discrete Cosine Transform (DCT):-}

DCT was firstly introduced by Ahmed, Natarajan and Rao in 1974 and found in his paper entitled "On image processing and a discrete cosine transform". Discrete Cosine Transform (DCT) was used to convert a signal domain into a frequency domain (Anila, S 2010)

\section{DCT 1 Dimension:-}

DCT 1 Dimension C (u) is defined as follows.

$$
\mathrm{C}(\mathrm{u})=\sqrt{\frac{2}{n}} \alpha(u) \sum_{x-0}^{N-1} f(x) \cos \left[\frac{\pi(2 x+1) u}{2 N}\right]
$$

For $\mathrm{u}=0.1,2, \ldots, \mathrm{N}-1$

In the same way, backwards DCT can be defined as follows.

$$
f(\mathrm{x})=\sqrt{\frac{2}{n}} \sum_{x=0}^{N-1} \alpha(u) C(u) \cos \left[\frac{\pi(2 x+1) u}{2 N}\right]
$$

For $\mathrm{x}=0.1,2, \ldots, \mathrm{N}-1$ 
With $\alpha(\mathrm{u})$ expressed as follows.

$$
\alpha(\mathrm{u})=\left\{\begin{array}{l}
\frac{1}{\sqrt{2}} \text { for } \mathrm{u}=0 \\
1 \text { for } \mathrm{u} \neq 0
\end{array}\right.
$$

The numbers resulted by DCT transformation do not contain any imaginary elements. DCT of the image example 1dimension $\mathrm{f}(\mathrm{x})=(3,4,4,5)$ is as follows

$$
\begin{aligned}
c(0) & =\sqrt{\frac{2}{4}} \frac{1}{\sqrt{2}} \sum_{x=0}^{3} f(x) \cos \left[\frac{\pi(2 x+1) 0}{8}\right] \\
& =\frac{1}{2}(f(0)+f(1)+f(2)+f(3))=\frac{1}{2}(3+4+4+5)=8 \\
c(1) & =\sqrt{\frac{2}{4}} 1 \sum_{=0}^{3} f(x) \cos \left[\frac{\pi(2 x+1) 1}{8}\right] \\
& =\sqrt{\frac{1}{2}}(3(0,92)+4(0,38)+4(-0,38)+5(-0,92))=\sqrt{\frac{2}{2}}(-1,84)=-0,71 \\
C(2) & =\sqrt{\frac{2}{4}} 1 \sum_{x=0}^{3} f(x) \cos \left[\frac{\pi(2 x+1) 2}{8}\right] \\
& =\sqrt{\frac{1}{2}}(3(0,71)+4(-0,71)+4(-0,71)+5(-0,71))=0 \\
c(3) & =\sqrt{\frac{2}{4}} 1 \sum_{x=0}^{3} f(x) \cos \left[\frac{\pi(2 x+1) 3}{8}\right] \\
& =\sqrt{\frac{1}{2}}(3(0,38)+4(-0,92)+4(-0,92)+5(-0,38))=-0,76
\end{aligned}
$$

Thus, the image $\mathrm{f}(\mathrm{x})=(3,4,4,5)$ after getting a cosine transformation 1 Dimension $\mathrm{C}(\mathrm{u})=(8,0.76,0,-0.76)$.

\section{Method:-}

\section{Datasheet:-}

The data used in this study consisted of a set of file of face image used as training and a set of file of face image used as a test. The process of sampling usied the Digital Camera XLR Nikon D90 with a distance of 2 meters, File of face image used was a file with format bmp. The reason for choosing this because the bmp image format was the standard default in image processing on the Windows operating system.

\section{Research Stages :-}

The research stages were conducted by analyzing the performance of feature orde 1(Feature Statistics), performance of feature orde 2 (Featuring Haralic), Combination Performance of Feature orde 1 (Feature Statistics) and Feature orde 2, Combination Performance of Discrete Cosine Transform (DCT ) with Feature orde 1 (Feature Statistics), and Discrete Cosine Transform (DCT) combination with Feature orde 2 (Feature Haralic) and combination performance between feature orde 1 (Feature Statistics), feature orde 2 (Feature Haralic) and Discrete Cosine Transform (DCT). By front facial orientation, the position of $15^{\circ}$ left and right, $30^{\circ}$ left and right and $45^{\circ}$ left and right.

\section{Recognition of Face Image with Extraction of feature orde 1:-}

The steps of facial image recognition with extraction of feature order 1 can be seen in picture 2 .

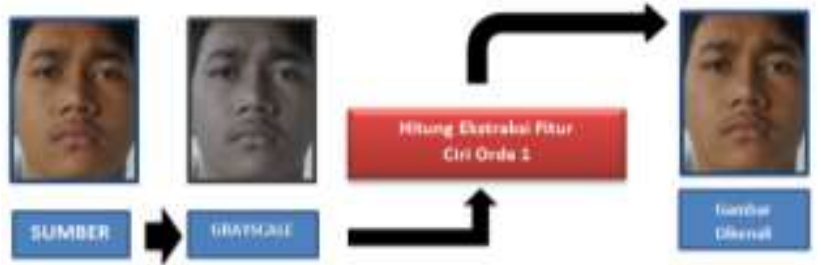

Figure 2:- Facial image rocognition with Extraction of feature orde 1 
At this stage, the system receives input face image, then the system will perform the process of grayscale to simplify the calculation where the input image has three channels that is channel R, G, B, after Grayscale works, the image will be a channel named as Grayscale channel, then that is reprocessed to perform extraction calculation of feature orde 1, after that calculating by training image pattern and testing image pattern, the recognizable face pattern is kind of face pattern of which calculation has highest percentage.

\section{Facial Image recognition With Extraction of feature orde 2:-}

The steps of facial image recognition with feature extraction of feature orde 2 can be seen in figure 3 .
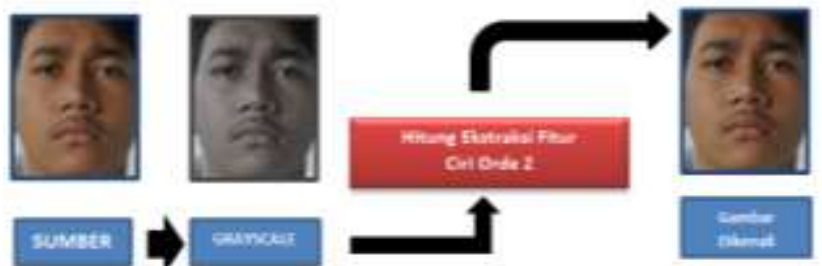

Extraction of feature orde :-

Figure 3:- Facial image rocognition with

At this stage, the system functions to receive input face image, then the system will perform the process of Grayscale to simplify the calculation where the input image has three channels that is channel, R, G, B, after grayscale works, the image will be a channel named as Grayscale channel, then that is reprocessed to perform extraction calculation of feature orde 2, after that calculating by training image pattern and testing image pattern, the recognizable face pattern is kind of face pattern of which calculation has highest percentage.

\section{Facial Image Recognition with Extraction Combination of feature orde 1and 2:-}

The steps of facial image recognition with the extraction combination of feature orde 1 and 2 can be seen in picture 4.

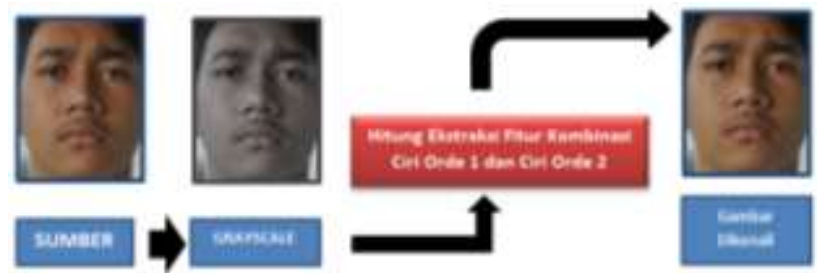

Figure 4:- Facial image recognition with

The extraction combination of feature orde 1 and 2:-

At this stage, the system functions to receive facial image input, then the subsequent system will perform the process of Grayscale to simplify the calculation, where the input image has three channel of R, G, B, after grayscale work, the image will be a a channel named as Grayscale channel, then that is reprocessed to calculate Extraction of feature order 1 and 2, after that calculating by training pattern and testing image one, the recognizable face pattern is kind of the face pattern of which the calculation has highest percentage.

Facial Image Recognition with the Extraction Combination of Feature orde 1 and DCT:-

The steps of face recognition with the extraction combination of feature orde 1 and DCT can be seen in figure 5 .
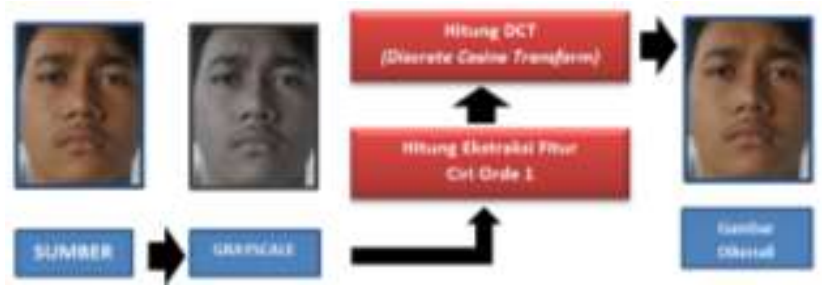

Figure 5:- Facial image recognition with the extraction combination of feature orde 1 and DCT features 
At this stage, the system functions to receive facial image input, then the system will perform the process of Grayscale to simplify the calculation, where the input image has three channels that is channel R, G, B, after Grayscale works, the image will be a channel named as Grayscale channel, then that is reprocessed to calculate Extraction of feature order 1 after that transformed using Discrete Cosine Transform (DCT). The gained value weight will be calculated by training pattern and image testing pattern. The recognizable face pattern is the kind of face pattern that has calculation of the highest percentage.

Facial Image Recognition with the Extraction Combination of Feature Orde 2 and DCT:-

The steps of face recognition with the extraction combination of feature orde 2 and DCT can be seen in figure 6
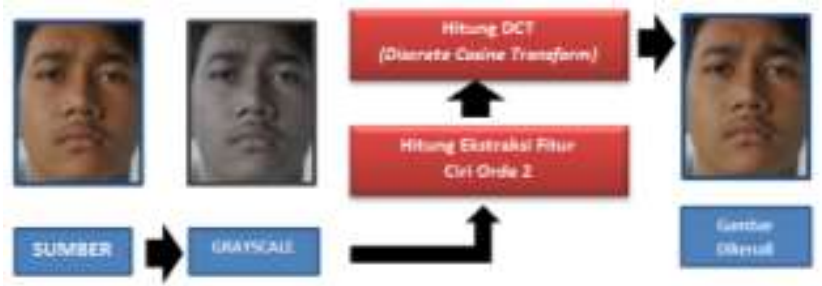

Figure 6:- Face image recognition with the extraction combination of feature order 1 and DCT

At this stage, the system receives facial image input, then the system will perform the process of Grayscale to simplify the calculation where the input image has three channel that is R, G, B, after grayscale works, the image will be a channel named as Grayscale chanel, then that is reprocessed to calculate Feature Extraction 2 after that transformed using discrete cosine transform. The gained value weight will be calculated by training pattern and image testing pattern. The recognizable face pattern is kind of face pattern of which calculation has the highest percentage

\section{Facial Image Recognition with the Extraction Combination of feature orde 1, 2 and DCT:-}

The steps of face recognition with the extraction combination of feature orde 1,2 and DCT can be seen in figure 7.
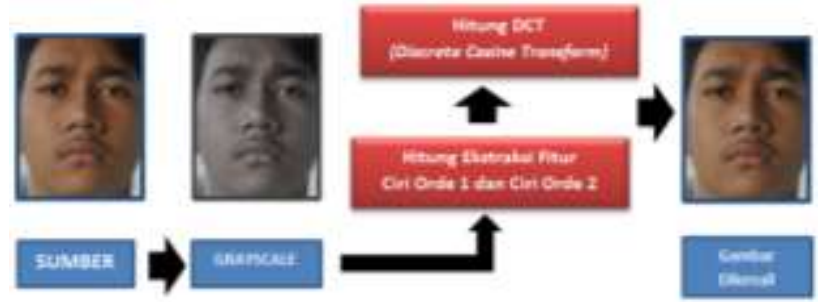

Figure 7:- Facial image recognition with The extraction combinations of feature orde 1, 2 and DCT

At this stage, the system function to receive face image input then the system will perform the process Grayscale to simplify the calculation where the input image has three channels that is channel $\mathrm{R}, \mathrm{G}, \mathrm{B}$, after grayscale work, the image will be a channel named as Grayscale channel, then that is reprocessed to calculate Extraction of feature orde 1 and 2 after that transformed using Discrete Cosine Transform (DCT). The gained value weight will be calculated by training pattern and image testing pattern. The recognizable face pattern is kind of the face pattern of which the calculation has the highest percentage.

\section{Results and Discussion:-}

\section{Results:-}

The results of this research was formed of facial image recognition using the extraction of feature orde 1 and 2 , combination of feature orde 1 and 2, Combination of Discrete Cosine Transfor (DCT) with feature orde 1. Combination of Discrete Cosine Transfor (DCT) with feature orde 2. Combination of Discrete Cosine Transfor (DCT) with feature orde 1 and 2.

The data sampling of face image used Nikon D90 SLR camera. This research was conducted at SMA Yayasan Pendidikan Shafiyyatul Amaliyyah (YPSA) which is located at Jalan Setiabudi No 191 Medan Sunggal North Sumatra. The image used as the input only had a face object without any other objects. The number of samples was 
1400 images which will be divided into two parts, 840 (60\%) of the images were used for testing and 560 (40\%) were used for training. The face images must be recognized as follows.

Face image with orientation $45^{\circ}, 30^{\circ}, 15^{\circ}$ left.

2. Face image with orientation $0^{\circ}$.

3. Face image with orientation $45^{\circ}, 30^{\circ}, 15^{\circ}$ right.

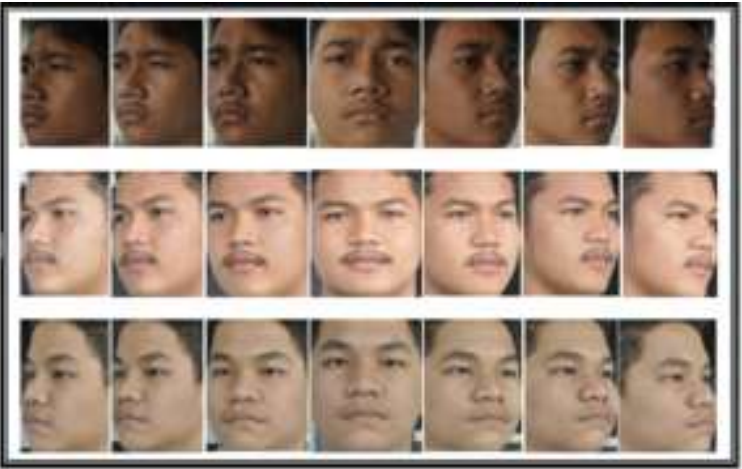

Figure 8:- Samples of the face image from the digital camera.

\section{Result of Feature Weight and Energy:-}

The extraction of feature orde 1 or 2 extracted the result of Grayscale image so as to obtain feature weight, whereas DCT, the value contained in the value of feature orde 1 and 2 will be transformed to obtain an energy value. The weight of features and energy will be saved into the dataset which will be used as the matching weight when testing process. In this case, the sample of face images used as training data were 840 samples from 40 different face patterns.

The overall extraction results of feature orde 1,2 and energy from Discrete Cosine Transfor (DCT) can be seen in Figure 9.

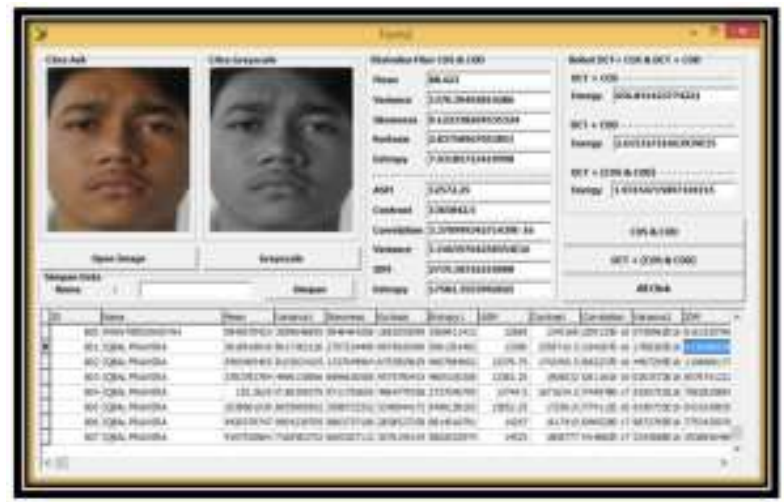

Figure 9:- Extraction results of feature orde 1,2 and energy from Discrete Cosine Transform (DCT)

\section{Test Results:-}

The test was conducted on 560 samples of face images with seven categories that was face image oriented $45^{\circ}$ left, $30^{\circ} \mathrm{left}, 15^{\circ}$ left, $0^{\circ}, 15^{\circ}$ right, $30^{\circ}$ right, $45^{\circ}$ right. To simplify the complex calculation process, Borland-Delphi $\mathrm{XE}$ software is considerably needed as testing.

Each stage of image computing process was converted into program using Borland-Delphi XE software.

This functioned to speed up the processing and calculation of data computation of image input.

The figure 10 showed some object identification test results from the input image. but some of the test results of the sample image data had errors in the identification process. 


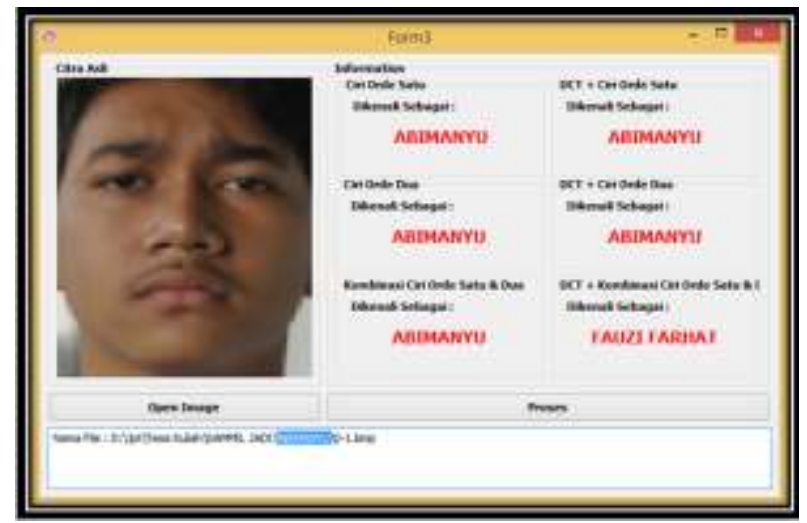

Figure 10:- Results of facial image recognition

\section{Measurement of Algorithm:-}

Based on the results of research, the performance of the algorithm is very influential to the feature extraction stage, observation to the face pattern of reference for testing, the complexity of the object on the image and the success level of the algorithm in mapping the vector of the input face pattern. The face owner can be well-recognized by the method if the feature extraction value of the input pattern is almost similar to the feature extraction value of the test pattern. The results of each method discussed can be seen in Figure 10.

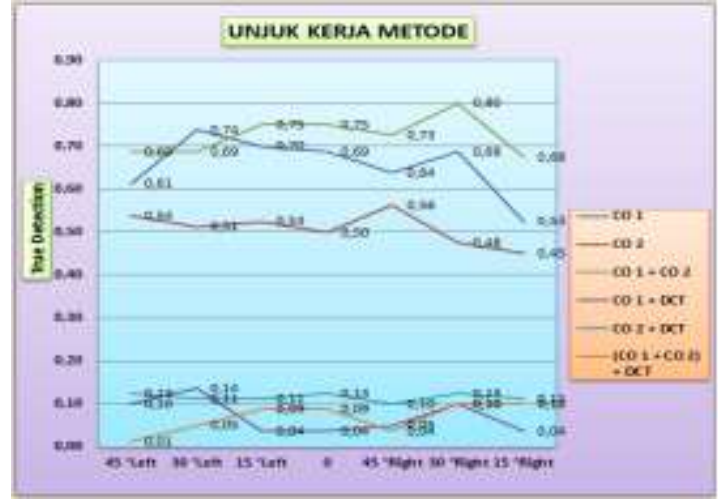

\section{Results:-}

In figure 11, the graph illustrated results of the facial pattern recognition on an image for each method having different level of accuracy. In the image with orientation $45^{\circ}$ to the left, The Extraction of the feature 1 had an accuracy level of $61.25 \%$, for feature extraction 2 had an accuracy level of $53.75 \%$, for combination between feature orde 1 and 2 had accuracy level of $68.75 \%$, combination of DCT with feature orde 1 had accuracy of $10 \%$ and combination DCT feature orde 2 had an accuacy of $12.5 \%$,meanwhile the combination of DCT with extraction of feature orde 1 and 2 obtained the lowest accuracy level of other methods of $1.25 \%$. For an image orientated $45^{\circ}$ to the left, the best method was a combination of feature order 1 and 2 with a result of $68.75 \%$.

From the image oriented a $30^{\circ}$ to the left, extraction of feature orde 1 had an accuracy level of $73.75 \%$, for extraction of feature orde 2 had accuracy level of 51.25\%, for combination between feature orde 1 and 2 had accuracy level of $68.75 \%$, DCT with a feature orde 1 had accuracy level of $13.75 \%$, a combination of DCT with a feature order 2 had accuracy level of $11.25 \%$ meanwhile the combination of DCT with extraction of feature orde 1 and 2 obtained the lowest accuracy level of other methods that is $5 \%$. For images with orientation a $30^{\circ}$ to the left, the best method was the extraction of feature orde 1 with a result of $73.75 \%$.

From the image oriented a $15^{\circ}$ to the left, the extraction of feature orde 1 had an accuracy level of $70 \%$, for the extraction of feature orde 2 had accuracy level of $(52.25 \%)$, for the combination of feature 1 and 2 had accuracy level of $75 \%$, DCT combination with feature orde 1 had accuracy level of 3,75\%, DCT combination with feature orde 2 had accuracy level of $11,25 \%$, meanwhile combination of DCT with the extraction of feature orde 1 and 2 
obtained lowest accuracy of other methods of $8,75 \%$. For an image with orientation a $15^{\circ}$ to the left, the best method was a combination between feature orde 1 and 2 with results of $75 \%$.

From an image oriented $0^{\circ}$, the extraction of features orde 1 had an accuracy level of $68.75 \%$, for extraction of feature orde 2 had accuracy level of 50\%, for a combination of feature orde 1 and 2 had accuracy level of 75\%, DCT combination with feature orde 1 had accuracy level of $(3,75 \%)$, DCT combination with feature orde 2 had accuracy level 12,5\%, meanwhile combination of DCT with extraction of feature orde 1 and 2 obtained the lowest accuracy of other methods of $8.75 \%$. For the image oriented $0^{\circ}$ to the left, the best method is a combination between feature orde 1 and 2 with the result of $75 \%$.

From an image oriented $15^{\circ}$ to the right, the extraction of feature orde 1 and 2 had an accuracy level of $52.50 \%$, for extraction of feature orde 2 had accuracy level of $45 \%$, for a combination of feature orde 1 and 2 had accuracy level of $67,50 \%$. DCT combination with feature orde 1 had accuracy of $3.75 \%$, a DCT combination with feature orde 2 had accuacy level of $11.25 \%$. Meanwhile the combination of DCT with extraction of feature orde 1 and 2 orde obtained the lowest accuracy of the other methods that is $10 \%$. For image oriented $15^{\circ}$ to the right. The best method is a combination of feature orde 1 and 2 with results of $67,50 \%$.

From an image oriented a $30^{\circ}$ to the right, the extraction of feature orde 1 had an accuracy level of $68.75 \%$ for extraction of feature orde 2 had accuracy level of 47,50\%, for a combination of feature orde 1 and 2 had accuracy level of $80 \%$, DCT combination with feature orde 1 and $2(10 \%)$, DCT combination with feature 2 had accuracy level of $12.50 \%$, meanwhile the combination of DCT with extraction of feature orde1 and 2 obtained the lowest accuracy of the other method of $10 \%$. For images oriented a $30 \%$ to the right, the best method is a combination of feature order 1 and 2 with results of $80 \%$.

From an image oriented a $45^{\circ}$ to the right, the extraction of feature orde 1 had an accuracy level of $63.75 \%$, for feature extraction 2 had accuracy level $56.25 \%$, for a combination of feature 1 and 2 had accuracy level of $72,5 \%$ ) for DCT combination with feature orde 1 had accuracy level 5\%, DCT combination with feature orde 2 had accuracy level 10\%. Meanwhile the combination of DCT with the extraction of feature orde1 and 2 had the lowest accuracy of the other methods that is $3.75 \%$. For an image oriented a $45{ }^{\circ}$ to the right. The best method is a combination of feature orde 1 and 2 with the result of $(72.5 \%)$.

\section{Discussion:-}

From the result of the research, the combination of the extraction of feature orde 1 and 2 contributed to better facial recognition result than the extraction of feature orde 1 and 2. Discrete Cosine Transform (DCT) combination with feature 1, Discrete Cosine Transform (DCT) with feature orde 2 and a combination of Discrete Cosine Transform (DCT) with feature orde 1 and 2

\section{Contributions:-}

Based on the results on seven models tested such as feature orde 1 and feature orde 2, combination of feature orde 1 and 2, combination of feature orde 1 with Discrete Cosine Transform (DCT), combination of feature orde 2 with Discrete Cosine Transform (DCT) and a combination of feature orde 1, 2 and Discrete Cosine Transform (DCT),. So this research can propose the best model in facial image pattern recognition in various angles tested.

This research contributed to the recognition of facial image patterns in various angles by using a combination of extraction values on feature and image transformation to obtain better accuracy level and be eligible as the reference for further research within a combination of various extraction features

\section{Conclusion:-}

Based on the results of research, it can be concluded as follows:

1. Based on the research, face image can be identified by using the extraction of feature orde1 and 2, combination of feature orde 1 and 2, Combination of DCT with feature orde 1, combination of DCT with feature orde 2 and the combination of DCT with feature orde 1 and 2.

2. The facial image recognition for the feature order 1 had an accuracy level with the percentage of $65.54 \%$, for the feature orde 2 had accuracy of $50.89 \%$, for the combination of feature orde 1 and 2 , had accuracy of $72.50 \%$, for combination of feature orde 1 and Discrete Cosine Transform (DCT) had accuracy of 7.14\%, for 
combination of feature orde 2 and Discrete Cosine Transform (DCT) had accuracy $11.61 \%$, and for a combination of feature orde 1 and 2 with Discrete Cosine Transform (DCT), had accuracy 6.79\%.

3. From percentage above, the combination of Discrete Cosine Transform (DCT) against Feature Extraction is not suitable for facial image recognition.

\section{Reference:-}

1. Gonzalez, R.C., Woods, R.E. 1992. Digital Image Processing. Addison - Wesley Publishing Company, USA.

2. Fadlisyah. 2013. Sistem Pendeteksian Wajah Pada Video Menggunakan Jaringan Adaptive Linear Neuron (Adaline). Program Magister Teknik Elektro. Universitas Sumatera Utara.

3. Zhou, H, Wu, J \& Zhang, J. 2010. Digital Image Processing, Part I. The Ebook Company.

4. Bino Sebastian V1, A. Unnikrishnan and Kannan Balakrishnan. 2012. Grey Level Co-Occurrence Matrices: Generalisation And Some New Features. International Journal of Computer Science, Engineering and Information Technology (IJCSEIT), Vol.2, No.2, April 2012

5. Anila, S dan Devarajan, N. 2010. Simple and Fast Face Detection System Based on Edges. International Journal of Universal Computer Sciences (Vol.1-2010/Iss.2), pp. 54-58.

6. R. Haralick, K. Shanmugam, and I. Dinstein, (1973) "Textural Features for Image Classification", IEEE Trans. on Systems, Man and Cybernetics, SMC-3(6):610-621

7. Angkoso C.V, Nurtanio I, Purnama K.E, Purnomo M.H. 2011. Analisa Tekstur Untuk Membedakan Kista Dan Tumor Pada Citra Panoramik Rahang Gigi Manusia. The $12^{\mathrm{TH}}$ Seminar On Intelligent Technology And ITS Applications. ISSN 2088 - 4796

8. Muliawan, M.R., Irawan, B. \& Brianorman, Y. 2015. Implementasi Pengenalan Wajah Dengan Metode Eigenface Pada Sistem Absensi. Jurnal Coding, Sistem Komputer Untan Volume 03, No. 1 (2015). Hal 41-50 ISSN : 2338-493X

9. Nugroho, Setyo. 2004. Sistem Pendeteksi Wajah Manusia pada Citra Digital. Tesis S2 Ilmu Komputer Program Pascasarjana Universitas Gadjah Mada Jogjakarta.

10. Permadi Y, Murinto. 2015 Aplikasi Pengolahan Citra Untuk Identifikasi Kematangan Mentimun Berdasarkan Tekstur Kulit Buah Menggunakan Metode Ekstraksi Ciri Statistik. Jurnal Informatika Vol. 9, No. 1, Jan 2015

11. Suprianto, D. 2013. Sistem Pengenalan Wajah Secara Real-Time, dengan Adaboost, Eigenface PCA \& MySql. Malang. Universitas Brawijaya Malang.

12. Uyun Shofwatul, Fadzlur M Rahman. 2013. Pengenalan Wajah Dua Dimensi Menggunakan Multi-Layer Perceptron Berdasarkan Nilai PCA dan LDA. Jurnal Ilmiah Komputer dan Informatika (KOMPUTA) Vol. 2, No. 1, Maret 2013

13. Yang, M.H., Kriegman, D., Ahuja, N. 2002. Detecting Faces in Images: A Survey. IEEE Trans. Pattern Analysis and Machine Intelligence, vol. 24,no. 1. 